Review

\title{
Cancer: We Should Not Forget The Past
}

\author{
Anna Di Lonardo ${ }^{1}$, Sergio Nasi² ${ }^{2}$ Simonetta Pulciani ${ }^{1}{ }^{凶}$ \\ 1. National Center for Immunobiologicals Research and Evaluation, Istituto Superiore di Sanità, Viale Regina Elena 299, Rome 00161, Italy. \\ 2. Istituto di Biologia, Medicina molecolare e Nanobiotecnologie (IBMN) CNR, Sapienza University, Rome, Italy.
}

\begin{abstract}
$\triangle$ Corresponding author: Simonetta Pulciani, simonetta.pulciani@iss.it.
(C) Ivyspring International Publisher. This is an open-access article distributed under the terms of the Creative Commons License (http://creativecommons.org/ licenses/by-nc-nd/3.0/). Reproduction is permitted for personal, noncommercial use, provided that the article is in whole, unmodified, and properly cited.
\end{abstract}

Received: 2014.08.14; Accepted: 2014.09.19; Published: 2015.01.01

\begin{abstract}
Cancer has been in existence longer than human beings, and man has been facing the illness ever since he made his appearance on Earth. Amazingly, the first human cancer gene was cloned only thirty years ago. This, and other extraordinary scientific goals achieved by molecular cancer research in the last 30 years, seems to suggest that definitive answers and solutions to this severe disease have been finally found. This was not the case, as cancer still remains to be defeated. To do so, cancer must be first understood.

This review highlights how cancer onset and progression has been tackled from ancient times to present day. Old theories and achievements have provided the pillars of cancer understanding, in laying the basis of 'modern era' cancer research, are discussed. The review highlights the discovery of oncogenes and suppressor tumor genes, underlining the crucial role of these achievements in cancer diagnosis and therapies. Finally, an overview of how the modern technologies have given impetuous to expedite these goals is also considered.
\end{abstract}

Key words: Cancer theories, oncogenes, genomics.

\section{Introduction}

The scientific path taken to understand cancer is paved with thousands of theories and scientific findings, from the time of Hippocrates to genomics today. Many of these are fundamental in our modern approaches to the disease.

Chemical carcinogenesis was brought to light with the observations of Paracelsus on cancer onset and environmental exposure to chemicals undertaken over six centuries ago (1-3). The relationship between cancer and chemicals captured the interest of scientists since the $18^{\text {th }}$ century, and this having had a greater impact in the last century. This knowledge, previously unproved, is a reality in today's research and plays a vital role in the understanding of cancer.

Exactly a century ago, in the book, Zur Frage der Entstehung Maligner Tumoren, Boveri presented his theory on cancer that was based on chromosomal abnormality (4-6).
Boveri had no knowledge on the chromosome structure; however, his theory today is considered a pillar of modern molecular approaches to cancer. The discovery of the DNA structure and the achievements of molecular biology have reaffirmed Boveri's theory and given technological support to developments in this field.

Without doubt, the first human transforming gene, and more broadly, oncogenes and anti-oncogenes, had been previously theorized by Theodor Boveri.

Nowadays, even though scientific research moves ahead rapidly, cancer still needs solid and reliable solutions. Nevertheless, science should look back to historical achievements in advancing new theories and data. Considering the past, and reviewing the milestones of every scientific finding could help in molding future experimental approaches in cancer research. 


\section{From Pre-History to Boveri}

Cancer has been in existence on Earth even before the appearance of man, as evidenced by paleontological findings of tumors in animals $(1,2)$.

The first description of human cancer can be found in the Edwin Smith Papyrus dated 3000 BC that illustrated a case of breast cancer. Other documented proof includes the Ebers Papyrus dating from 1500 BC that describes several types of tumors concerning skin, uterus, stomach, and rectum. These old Egyptian documents recorded cancer as a grave incurable disease and associated it to 'the curse of the gods' (1). Interestingly, this belief continued to be accepted right up to Hippocrates (460-370 BC), who postulated the earliest scientific theory about cancer. Hippocrates hypothesized that this disease was correlated to an excess of black bile. He believed that cancers, and more broadly any disease, developed whenever the balance in the four body humours (blood, phlegm, yellow bile, and black bile) were lost. Whenever black bile became the dominant humours in some part of the body, this developed cancer.

Hippocrates theory established the foundations of experimental approaches in understanding and confronting cancer, thereafter practiced by all scientists. Claudius Galen (130-200), a Greek physician who practiced medicine in Rome, implemented the Hippocrates theory. He proposed that black bile caused incurable cancer, whereas yellow bile caused curable cancer.

Additionally, the terms and words used to name this disease, and whatever it was associated with, were created by these early 'scientists'. Hippocrates used the word carcinoma, comparing the disease to a crab (Kapkivos) that adheres to its surroundings with his claws $(1,2)$. The physician Celsus (25 BC-50), later translated this word into cancer, the Latin word for crab. Galen (130-200) described tumors using the Greek term for swelling, oncos.

In the Middle Ages, religious beliefs inhibited the advancement of knowledge, and people began to believe that cancer was an infectious disease.

Eventually, medical science gained a foothold during the Renaissance when scientists began performing autopsies, combining the study of the human body and that of cancer, leading to important achievements. In the $16^{\text {th }}$ century, the anatomist Andreas Vesalius and others were able to demonstrate the non-existence of black bile. Nevertheless, Hippocrates' theory still continued to have great number of supporters, and it took some time before it was superseded by a new hypotheses. In the same century, Paracelsus studied tumors of mine workers, and suggested there were deposits of sulfur and arsenic salts in blood of these workers, causing their cancers
(1-3). At this time it was not known how the elements of the environment caused disease; however, this observation pre-empted the future of chemical carcinogenesis research, being the first association between the work environment and cancer.

A century later, Boerhaave suggested, '...that cancer was most likely induced by viruses present in water or in soil. Once acquired, the cancer viruses remained in the body, and they could be transferred by contagious infections or by heredity'. This theory was by no means new, as people during Middle Ages understood that cancer was a contagious disease. Moreover, at that time the term virus indicated some kind of toxic substance, therefore in this respect, Boerhaave's hypothesis was similar to that of Paracelsus. However, Boerhaave first introduced the new concept that cancer could be hereditary $(1,2)$.

In the $18^{\text {th }}$ century the Italian pathologist, G.B. Morgagni, founded scientific oncology by performing autopsies after death to identify the patient's disease. Consequently, he reported that cancer was the result of an 'organ lesion'.

Other scientists and surgeons suggested cancer was a destructive growth of the organ, caused by their internal structural transformation, or derived from coagulated lymph $(1,2)$.

During the $18^{\text {th }}$ century, different physicians expanded the hypothesis about the association between cancers and chemical exposure. Their observations had recalled the Paracelsus hypothesis, and this established the new and modern approach of cancer epidemiology. John Hill associated the use of snuff with nasal polyps. Bernardino Ramazzini associated breast cancer with reproductive factors $(1,2)$. Interestingly, in 1775 Percivall Pott noticed that chimney sweepers frequently developed cancer of the scrotum in later life, and suggested that soot was the cause of this type of cancer. In the last decades of the $19^{\text {th }}$ century, Ludwig Rehn, observed an association between exposure to the aniline dye and bladder cancer in industrial workers $(2,3)$.

The use of the microscope represented an opportunity for researchers to investigate tumors in great detail. Rudolf Virchow stated that 'cancer is a disease of cells', and David Hansemann proposed, 'The cell of the malignant tumor is a cell with a certain abnormal chromatin content' $(2,4,6)$.

At the beginning of the $20^{\text {th }}$ century, several researchers experimentally confirmed that specific chemicals in the workplace and environment were correlated with the carcinogenic process, demonstrating their multistage and multifactor nature. Katsusaburo Yamagiwa and Koichi Ichikawa, in 1915, were able to induce cancer in rabbits by applying coal tar to the skin of these laboratory animals (3). Addi- 
tionally, at this time Theodor Boveri had expanded the Hansemann theory. It is worthwhile to mention what Boveri wrote, 'tumor growth is based on ...... particular, incorrect chromosome combination which is the cause of the abnormal growth characteristics passed on to daughter cells' (4-6). Figure 1 shows the original book cover published in 1914.

A major milestone for modern era cancer was the discovery of the first tumor viruses $(7,8)$ in chickens by Ellerman and Bang (1908) and Peyton Rous (1911). These and other important achievements on cancer research, from prehistoric times up to present day are summarized by date in Table 1 . Of important note, in the beginning of 1900 external factors such chemical; radiation and viruses were accepted as etiological agents of cancer (3-8). Amazingly, both chemical and viral carcinogenesis produced the same results (9), since, independently, they provided evidence that tumors are correlated to mutated genes.

\section{From Boveri to Oncogenes and Anti- Oncogenes}

Ellerman and Bang in 1908, induced erythro-myeloblastic leukemia in healthy chickens by an acellular filtrate collected from diseased chickens $(7,8)$, which later proved to be an RNA virus. In 1910, Peyton Rous isolated a filterable agent from the sarcoma in the breast muscle of a Plymouth Rock hen. This agent was later named the Rous Sarcoma Virus (RSV) and was regarded as the first RNA tumor virus, as in the early 1900's leukemia was not considered a cancer.

However, the scientific world at this time was skeptical and did not note the importance of these developments. Fortunately, some researchers had persevered in this field achieving some important goals. For instance in 1936, R. Bittner demonstrated that the mammary carcinoma of $\mathrm{C} 3 \mathrm{H}$ mice was induced by viruses and this observation was fundamental in RNA tumor virus research $(7,8)$. Later, on 1953, L. Gross isolated the first virus inducing leukemia in mice $(7,8)$.

It is worthwhile to mention that in 1907 the Italian researcher, G. Ciuffo, demonstrated the transmission of human warts by inoculating himself with a cellular filtrate $(7,8)$. Later, these viral particles were characterized as a DNA virus. The significance of this finding was understood only many years later, when the association between cancer and some types of these viruses was demonstrated, currently known as papillomaviruses. DNA tumor virus research and more broadly of other human tumor viruses, will not be discussed in this review; however, in Table 1 the principal achievements in these fields are listed.

Cell culture techniques implementation and the definition of DNA structure have been crucial in determining infections and transformation mechanisms of these tumor viruses, permitting the isolation and characterizations of mutants (10-12). Table 2 shows the achievements on molecular biology and biochemistry from the end of 1800, up to the advent of the human genome. If Table 1 and Table 2 are compared, it becomes quite evident that the deeper knowledge of cellular molecular processes and the implementation of new experimental approaches were decisive in understanding present day tumor genetics. Figure 2 summarises the major achievements obtained in molecular cancer research and molecular biology.
Figure 1. Zur Frage der Entstehung Maligner Tumoren (1914) book cover, kindly provided by Bi.Ge.A.-Bologna University. 
Table 1: TIMELINE OF THEORIES AND ACHIEVEMENTS ON CANCER.

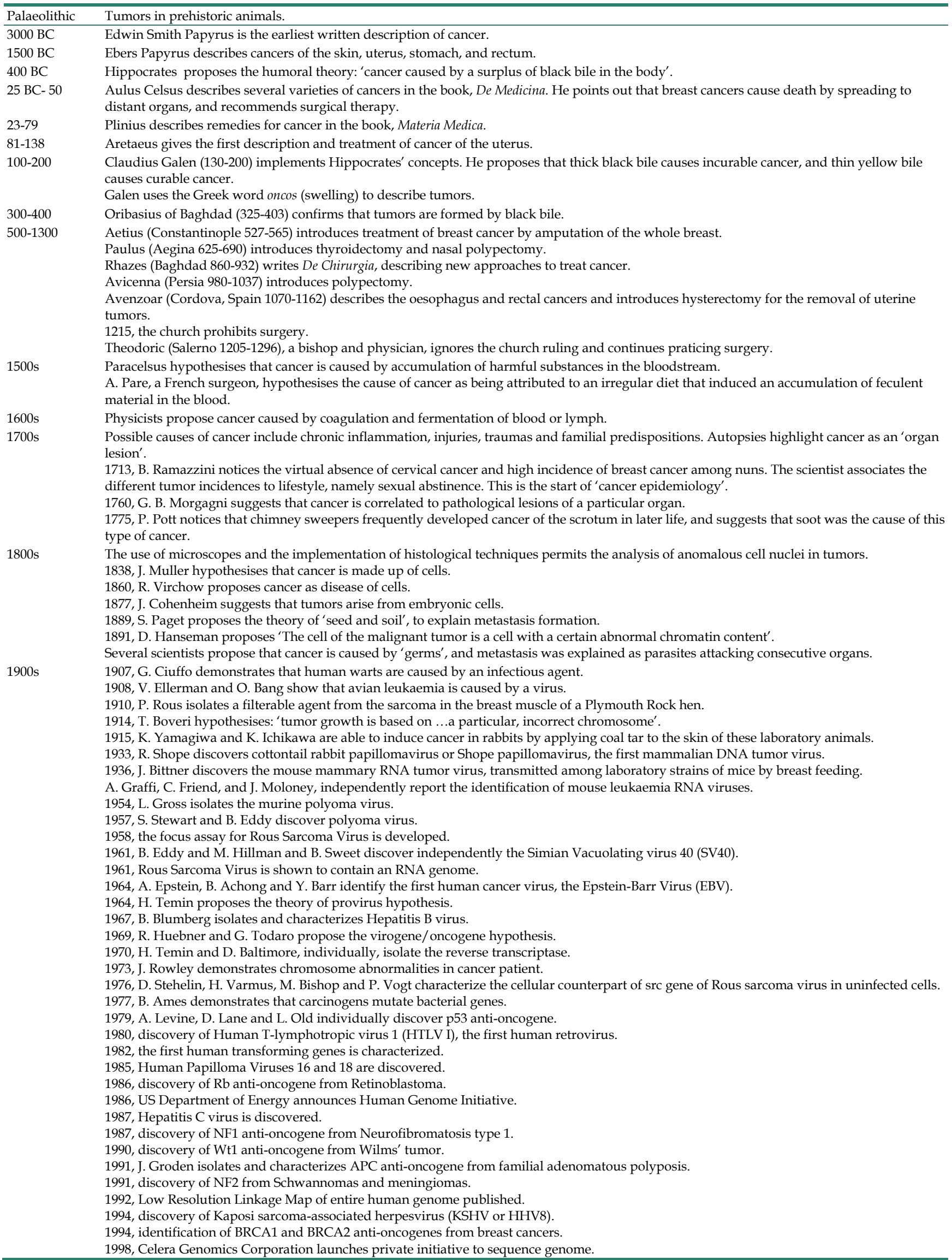


1999, Public genome project completes sequence of first chromosome, chromosome 22.

2001, Human genome draft version finished (3200 Mb).

2002, Presentation of human genome.

2007, First cancer exomes published.

2008, The Cancer Genome Atlas (TCGA) research network publishes first data from 206 glioblastoma samples, covering 601 genes.

2008, first whole cancer genome sequenced from cytogenetically normal Acute Myeloid Leukemia (AML), compared with normal somatic skin cell from same individual.

2008, Y. Chang and P. Moore develop a new method to identify cancer viruses based on computer subtraction of human sequences from a tumor transcriptome.

2009, publication of a second complete AML genome and genetic alterations tested in cohort of 187 additional AML tumor samples.

2009, exomic sequencing uncovers genetic risk factor for pancreatic cancer.

2010, first whole genome of a cancer cell line sequenced.

2010, sequencing of more than 3,500 genes in 101 renal cancer samples, connecting the genome and epigenome.

2010, whole genome sequencing of melanoma tumor and normal pair identifies UV-induced mutation.

2010, first publication of whole genomes from primary and metastatic tumor from one breast cancer patient.

2010, 70 whole cancer genomes or exomes sequenced.

Table 2: MOLECULAR BIOLOGY TIMELINE UP TO THE HUMAN GENOME PROJECT.

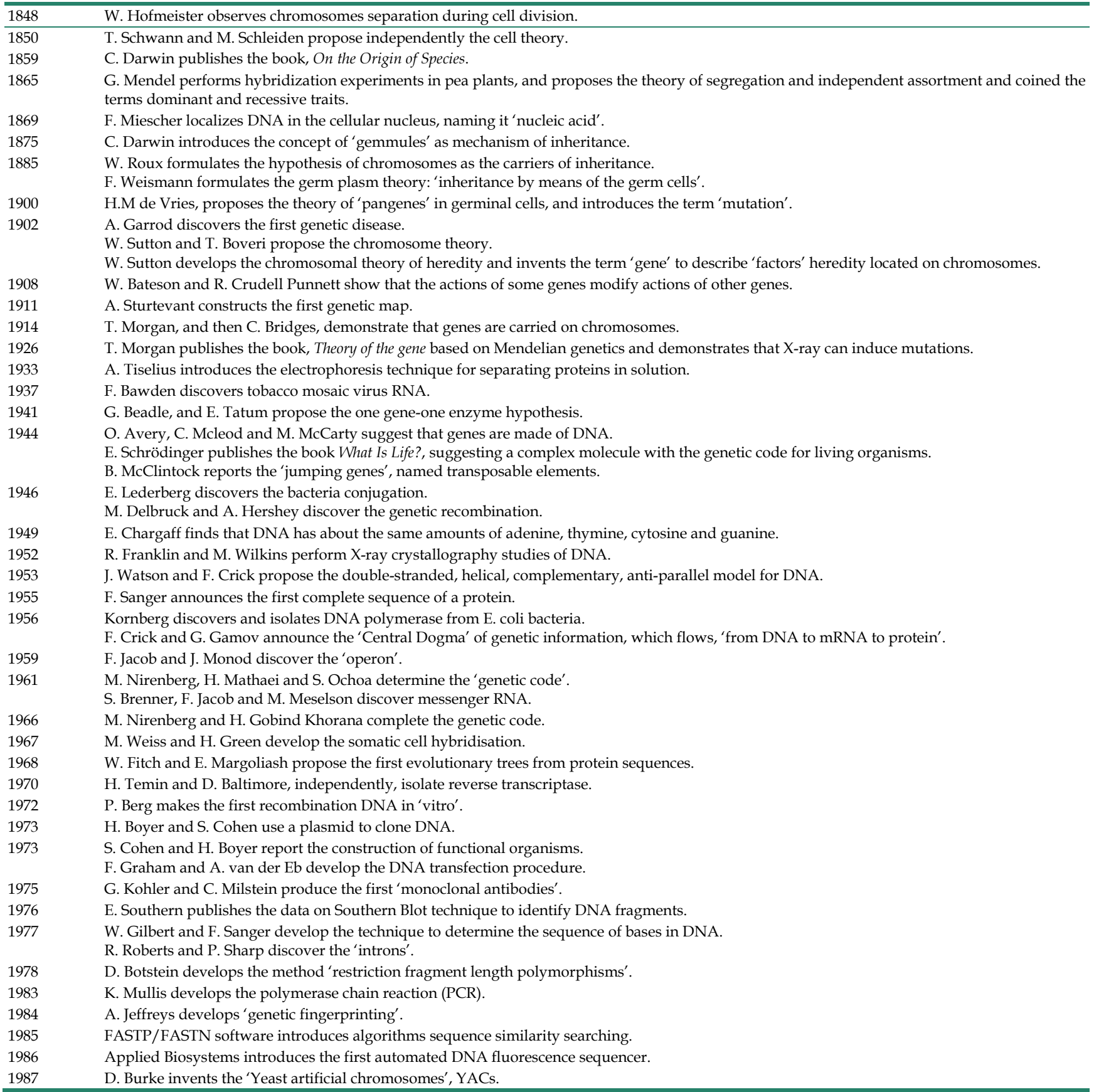




\begin{tabular}{ll}
\hline 1990 & Human Genome Project commences. \\
& S. Karlin and S.F. Altshul introduce BLAST, 'fast sequence similarity searching tool'. \\
& LC Tsui, F Collins, and J Riordan find the gene responsible for cystic fibrosis. \\
1991 & C. Venter and colleagues develop EST, 'expressed sequence tag sequencing'. \\
1992 & M. Simon introduces the use of BACs for cloning. \\
1996 & P. Brown of Stanford University presents the 'gene chip' containing 6116 different gene specific sequences of the yeast genome (Microarray). \\
& I. Wilmut presents Dolly, the first cloned living creature. \\
2001 & Human genome draft version finished (3200 Mb). \\
& Presentation of human genome.
\end{tabular}

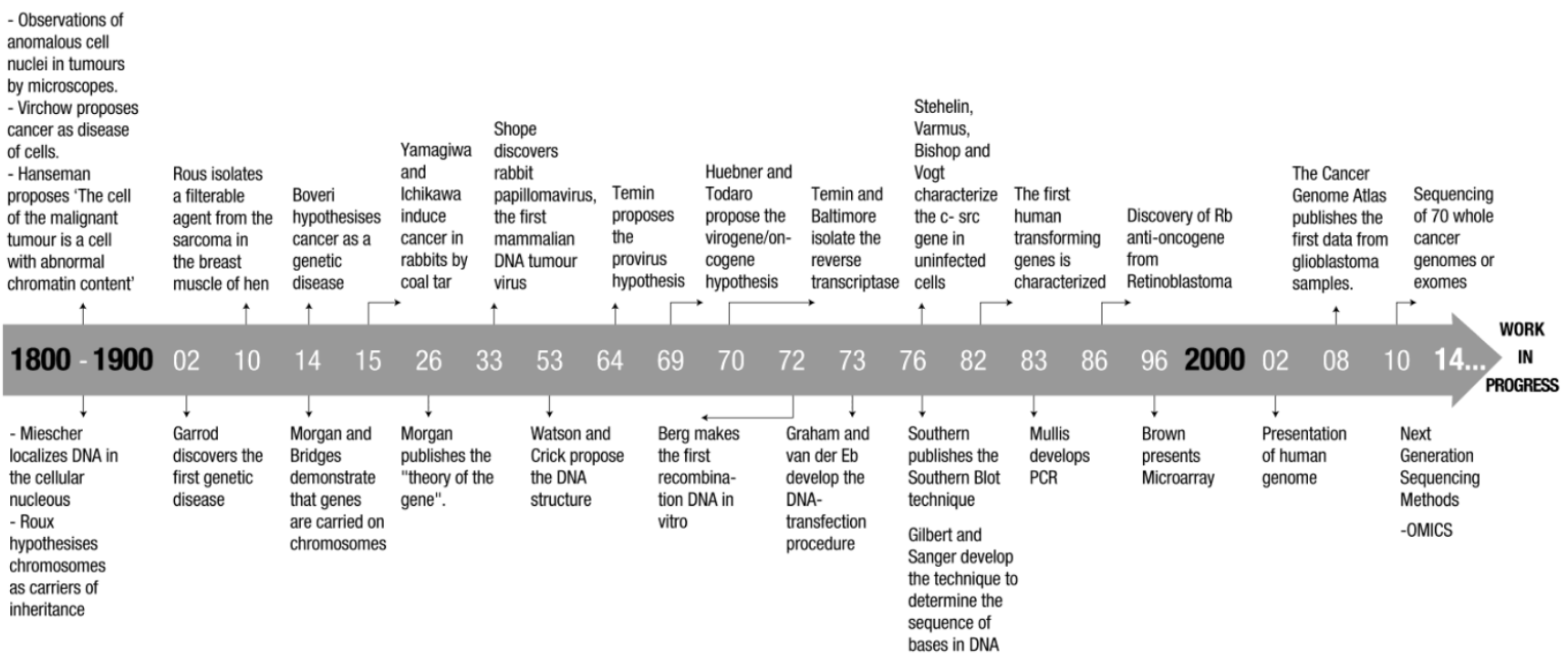

Figure 2. Milestones in molecular cancer research (upper part) and molecular biology (lower part).

In 1961, RSV was shown to contain an RNA genome (13), and it became the prototype, 'RNA tumor virus' (14). Moreover, experiments performed by Temin with actinomycin and amethopterin, inhibitors of nucleic acid, suggested that the virus replicated by transferring the genetic information of the infecting virus, from RNA to DNA, and back again to the RNA of the progeny virus (15).

These results have to be considered as a milestone in tumor virology, although the RNA genome of the virus represented a dilemma hard to resolve.

In 1964, Temin proposed the theory of provirus, '....virus enters a cell and directs formation of a DNA containing the genetic information of the virus. This new DNA, the provirus, then acts as a template for the formation of new nucleic RNA, for the virion.....' (16).

The provirus theory was based on the revolutionary hypothesis that RSV replicates through a synthetized DNA intermediate using as a template the RNA genome (17). Up to this time, no evidence existed on the possibility of transfering genetic information from RNA to DNA and back to RNA. Hence, this innovative model of viral replication did not receive much attention from the scientific community. However, researchers had the urgency to resolve the inexplicable results on RNA tumor virus replication obtained with inhibitors of nucleic acid synthesis. In 1969, Huebner and Todaro proposed the virogene/oncogene hypothesis. This theory postulated that DNA of most, or all of, the eukaryotic cells carried vertically transmitted RNA tumor virus information, this being known as virogene (18). These viral sequences contain the oncogene, which may transform normal cells into tumor cells. These RNA tumor viruses are present in a repressed form in the cells and they may be 'switched on' by various environmental factors, and also are dependent on the host genotype. The 'switching on' of these sequences can produce an infectious virus and/or induce the cellular transformation. The virogene hypothesis differs from the provirus hypothesis, since the latter implies that an exogenous virus infects the cell. Instead, the virogene/oncogene is part of the genetic background of all vertebrate cells. In 1970, Temin and Baltimore individually isolated the reverse transcriptase, which was able to mediate the RNA-dependent DNA synthesis $(19,20)$. This enzyme represented the key element of the provirus hypothesis, and after this event the RNA tumor viruses were renamed retroviruses.

Reverse transcriptase had definitively changed the approach in studying RNA tumor viruses and permitted new experimental methods in investigating their neoplastic mechanisms. In 1976, Dominique Stehelin, Harold Varmus, Michael Bishop, and Peter 
Vogt characterized the sequences of RSV responsible for its neoplastic potential, the src gene (21). Moreover, they demonstrated the cellular origin of this transforming gene, since its normal counterpart is present in the normal eukaryotic cells. Following this, many more transforming genes of other tumorigenic retroviruses were characterized, and their cellular origin confirmed. These achievements recalled the theory of virogene/oncogene by Huebner and Todaro, and these genes were actually named oncogenes, and their cellular counterpart proto-oncogene (22).

Around this time, Bruce Ames demonstrated that carcinogens could mutate bacterial genes (23). The experiments proved that carcinogens could damage the genes of target cells, confirming the theory that cancer cells carried mutant cellular genes, which may confer a growth advantage.

The achievements on the transformation mechanisms of retroviruses and the findings on the mutagen activity of carcinogens demonstrated that tumors had gene alteration as a common denominator, independent of their etiology $(6,22,23)$.

Researchers had felt the urge to go further, and formulated experimental protocols in defining possible relationships between viral oncogenes and genes mutated by physical and chemical carcinogens.

Early in the 1970s, Graham and van der Eb developed a procedure for gene transfer in mammalian cells (24). The researchers used this method to introduce DNA of virally transformed cells into NIH 3T3 recipient cells, obtaining foci of transformation in their recipient cells several weeks later (25). Hence, this approach appeared to be a suitable method to analyse the genetic background of cancer cells, and to eventually reveal the genes involved in the neoplastic process.

DNA transfection was then used to analyze the presence of transforming active sequences in DNA extracted from several chemically transformed 3-methylcholanthrene (3-MC) mouse-cell lines. This experiment yielded a large number of foci, and non-transforming or activated endogenous viruses being detected in these mouse cells. It was probable that the transforming activity was derived from a cellular gene mutated by the 3-MC into a transforming active allele (25).

Later, researchers used the gene transfer protocol to investigate the presence of active transforming genes in human tumor cell lines and primary tumors. Remarkably, three different research groups demonstrated that DNA extracted from human tumors cells lines could transform NIH/3T3 cells. Furthermore, the characterization of the transforming sequences detected in the cell line T24/EJ, established from a human bladder carcinoma, evidenced their homology to ras, the transforming gene of Harvey, and the Balb sarcoma viruses (Ha-ras) (26-28). Molecular comparisons between the human ras transforming gene and its normal allele revealed that the malignant potential was activated by a single point mutation. Also, the ras gene can acquire a transforming activity from mechanisms other than capture by retroviral sequences (9). Investigators continued with the transfection approach analyzing DNA extracted from human solid and hematopoietic tumors $(29,30)$. Surprisingly, most of the activated transforming sequences detected in these tumors were homologous to viral ras genes ( Ha-ras and Ki- ras), although these later experiments also revealed activated transforming sequences that did not have viral counterparts (30). Moreover, ras transforming sequences were detected also in animal tumors induced by chemical carcinogens $(9,31)$. These results rolled back again to the Boveri's concept of neoplastic process in consequence of genetic alterations.

In the mid-1980s, DNA-transfection experiments confirmed the old theories on cancer onset and development, and fitted in well with tumor virology and chemical carcinogenesis. Despite, these extraordinary achievements, investigators soon underlined the limits of viral transforming genes had been used to investigate at molecular level tumors and their cells. Many human sequence homologues of viral oncogenes were cloned and localized in human chromosomes. These molecular approaches highlighted the fact that human proto-oncogenes can acquire transforming activity and drive cells to the neoplastic phenotype if rearranged, translocated or amplified (22).

One of the most relevant examples is the translocated Philadelphia chromosome associated with chronic myelogenous leukemia, a hematopoietic tumor. This translocation involves the Abl gene on chromosome 9 and the BCR (breakpoint cluster region) gene on chromosome 22 (32). Also, Bukitt's lymphoma cells were shown to present three types of translocations, all involving a fragment from the end of the long arm of chromosome 8 , which can be translocated to the long arm of chromosomes 14, or eventually, to chromosomes 2 or 22 . The translocated fragment of chromosome 8 contains the myc gene. This myc sequence can be translocated to chromosome 14, near to the immunoglobulin heavy chain locus, or to chromosomes 2 or 22, near to the two immunoglobulin light chain genes $(33,34)$. Myc gene amplification was found in the human promyelocytic leukaemia line HL60, and other cancer lines (35).

Moreover, it was well known from cytogenetic analysis that tumor cells may show loss of genetic information. Researchers developed sophisticated 
protocols based on cell hybrids to investigate at molecular-level these genetic abnormalities. By cell hybridization of normal fibroblasts with the human cancer cells, HeLa non-tumorigenic clones were obtained, some of which reverted to neoplastic phenotype (36). Molecular cytogenetic analysis of these clones had evidenced that the transformed phenotype correlated with the loss of the fibroblast chromosomes 11 and 14. Together, these findings proved that neoplastic phenotype and loss of genetic sequences are correlated. Furthermore, the molecular characterization of retinoblastoma and Wilms' tumor evidenced deletions on both pairs of chromosomes 13 and 11, respectively $(37,38)$. Additionally, transfection of a normal allele of chromosomes 11 into tumorigenic Wilms' tumor cells can revert to their phenotype. The chromosomal locus/genes correlated with these two neoplasia had been cloned and characterized, following elaborate cloning strategies.

The genes, associated with retinoblastoma and Wilms' tumor development were named Rb1 and Wt1, respectively. Retinoblastoma and Wilms' tumor are both heritable and non-heritable tumors. Their characterization demonstrated that germ-line mutations are present in the heritable form $(22,37,38)$. However, this inherited mutation is not sufficient for tumor formation; a second mutational event is required. Similarly, for the development of non-heritable tumors, two somatic events must occur and inactivate both genes. These results proved the two-hit hypothesis of Knudson according to 'a complete inactivation of both alleles of a tumor-suppressor gene is required for cancer onset and development. .....'. Hence, these sentinel genes acting against tumors have been named anti-oncogenes or tumor suppressor genes $(39,40)$.

Characterization of the protein products of proto-oncogenes and tumor suppressor genes revealed their role in regulating intra- and extracellular signaling related to cell growth and division. Usually proto-oncogene products are correlated with cellular functions that stimulate cell growth and division. Tumor suppressor genes are normal genes, mainly devoted to the cellular processes correlated with cell growth inhibition and programmed cell death (apoptosis) $(6,22,33)$.

Mutation, amplification, deletion or translocation of these genes disrupt their function, leading to an uncontrollable growth and cancer $(6,22)$.

Moreover, epigenetic changes also contribute to carcinogenesis. These changes alter the DNA and associated proteins without changing the DNA sequence, modulating the chromatin structure and DNA accessibility. Through these mechanisms, epigenetic changes may alter the transcriptional status of cancer genes, or regions of chromosomes that control their expression, inducing the neoplastic process (41). Interestingly, anti-oncogenes are involved in tumor development induced by some DNA tumor viruses. These viruses code proteins that are capable of inhibiting tumor suppressor proteins. An example, is the binding between $\mathrm{p} 53$ protein and viral transforming proteins such E6 of oncogenic HPV $(40,42)$.

Boveri had predicted all these findings, when he wrote, '....Another possibility is that there is a specific inhibitory mechanism in every normal cell that only permits cell division to take place when this mechanism is overcome by some special stimulus...A tumor cell that proliferated without restraint would be generated if these 'inhibitory chromosomes' were eliminated' $(4,5)$.

\section{Past, Present and Future}

In 1914, Boveri wrote, 'It is conceivable that for any one cell type there is one particular abnormal combination of chromosomes that endows the cell with the properties of malignancy...', predicting cancer to be a complex multifaceted process. Today, it is understood that more than one gene/chromosomal alteration contributes to tumor development, and these must be known and characterized to fully comprehend the molecular process of tumor development.

In 1985, Dulbecco stated in support of these factors, 'A major gap in our understanding of cancer is how the activity of an oncogene is related to the events of progression. But, the first task is to ascertain whether the DNA of an advanced cancer is as heterogeneous as the phenotype of its cells. If we wish to learn more about cancer, we must now concentrate on the cellular genome........', and in consequence, he advocated the Human Genome Project (HGP) (43). As Dulbecco had foreseen, the sequencing of the human genome represented the corner stone for the construction of physical and genetic maps and the identification of genes involved in human cancer.

Integrating the knowledge on human genomes with the new powerful technologies for DNA sequencing and inspection of protein expressions (mass-spectrometry), has permitted the collection of large amounts of data on genetic alterations and aberrant gene expression correlated to onset and development of different cancers $(44,45)$. The Cancer Genome Atlas (TCGA, http://cancergenome.nih. gov/) and the International Cancer Genome Consortium (ICGC, https://icgc.org/) provide clinical data and the genomic profiles of thousands of normal and tumor samples for a variety of cancer types. This has enabled the identification of many novel cancer genes. The catalogue - that includes oncogenes, anti- 
oncogenes, epigenetic regulators, cell cycle-associated genes, DNA damage response/repair genes, metabolic regulators, and microRNAs - has not yet been completed (46-49). Cellular and genomic data from a variety of tumors have confirmed and highlighted their extraordinary heterogeneity. This heterogeneity has been evidenced among tumors from patients with the same cancer type, inter-patients heterogeneity, and within cancer cells of an individual patient's tumor, intra-tumor heterogeneity. Heterogeneity represents, indeed, a thorny challenge to overcome in order to provide clinics with a suitable cancer genomic data. This objective does not appear simple to attain. The inter-patient heterogeneity is most likely tied to the different genetic backgrounds and lifestyles, and they should be considered and evaluated. Therefore, a molecular investigation at single-patient level may be required for a correct diagnosis and optimal therapy $(48,49)$. Moreover, intra-tumor heterogeneity should also be taken into account, and the mechanisms producing it. To explain the intra-tumor heterogeneity, one of the proposed models is the 'clonal evolution model'. It assumes that different mutant clones acquire a survival advantage, because of the natural competition with other clones. Stochastic genetic or epigenetic changes are claimed as the most probable mechanisms conferring growth advantage to cancer cells. Likely, macro and micro-environments play an important role in the development of the subpopulations of cancer cells, enabling them to initiate and/or propagate the disease, or even to permit its remission $(50,51)$.

Recently, cancer stem cells (CSCs) have gained the interest of scientists as a good candidate and 'model' to investigate tumor heterogeneity. Much experimental evidence has highlighted the presence of CSCs in a broad spectrum of malignancies. These cells can self-renew, proliferate and differentiate. It has been suggested that some tumors may arise from small populations of CSCs that give rise to phenotypically diverse cancer cells, playing important roles in tumor heterogeneity, favoring growth, dormancy or recurrence, and metastasis (52). The CSCs imply that tumors are organized as an adult tissue, and their genetic heterogeneity of cancer propagating cells may derived from 'clonal evolution' within the stem cell pool by the Darwin's premise of 'natural selection'. These models of cancer initiation and spreading refers back to the 'seed and soil' and 'embryonal' theories proposed by Paget and Cohenhein, respectively, more than hundred years ago (Table 1). Moreover, they emphasize that a tumor is composed of complex mixtures of cells with various genetic alterations and functions. They then suggest a single-cell analysis as feasible approach to overcome the dubious evaluation caused by multiple mixtures of mutations within tumor cells. Nowadays, single-cell genomic sequencing and single-cell transcriptomic sequencing have been explored as potential techniques to investigate cancer heterogeneity. Single-cell genomic sequencing mainly focuses on the general landscape of mutations, such as single nucleotide variations, insertions, and deletions in a single cell (53). Single-cell transcriptomic sequencing can be useful for analyzing genetic network regulation, including differentiation, reprogramming and transdifferentiation. Single-cell transcriptomic sequencing can highlight transcriptomic alterations (mRNAs, microRNAs, retained introns, alternative splicings, long-noncoding RNAs and fusion genes) (50-53). Data coming from such analysis could be relevant in understanding the role and the fate of single cells in a tumor, mainly CSCs. These techniques, along with appropriate 'in vitro' and 'in vivo' CSCs models to mimic tumor growth, could give an insight into genetic alteration/modification. It could also provide an understanding of the gene regulation networks responsible for physiological functions, behaviors, and phenotypes in response to signals and microenvironmental changes. The incoming data could be useful for revising and making available the huge amount of genomics information for the world research community. Moreover, this information, when cross-referenced and integrated, could be crucial to define better personalized therapeutic strategies (48-53), as well as to design a broad spectrum of preventive and therapeutic strategies that are broadly relevant. The analysis of expressed biomarkers in the cancer is one of the most used approaches for the disease's treatment, and recently, particular attention has been given to CSCs, as a main factor in fighting cancer. Different therapeutic strategies have been developed and are being designed to attack the CSCs and to destroy their surrounding environment; some of these strategies are under preclinical and clinical evaluation. Some strategies rely on using monoclonal antibodies against surface markers that are different from normal stem cells. Monoclonal antibodies against these markers and conjugated with cytotoxic agents permit the targeting of the CSCs cells and eventually kill them.

CSCs cells play also an important role in chemo-resistance acquisition. To overcome this problem, the mechanism responsible for the chemo-resistance must be identified and characterized. One of the most recognized mechanisms is the efflux of cellular cytotoxic drugs by the ATP-binding cassette (ABC) transporter proteins. The trans-membrane proteins using the energy from the ATP hydrolysis expel the drugs from the cells. Studies are focused on molecular drugs capable of inhibiting 
the $\mathrm{ABC}$ transporter protein. Moreover, CSCs could be attacked modifying the specific pathways involved in apoptosis and resulting in suppression of cellular characteristics. Particular attention has to be given to the tumor micro-environment, since it plays a relevant role in CSCs growth and selection, as well as in protecting them from drugs. For instance, experimental evidence shows a protective role of bone stromal cells in B cell malignancies. Finally, several therapeutic approaches are focusing on the angiogenesis processes as a mechanism to control CSCs growth and differentiation.

A different strategy is to target genes that are affected in a high percentage of tumor types, such as Myc or Ras, and to which cancer cells appear to be 'addicted' (54, 55). Approximately 30\% of human tumors harbor a mutant Ras gene, with an altered GTPase activity. Targeting the catalytic domain of the Ras proteins is technically challenging. Therefore, many efforts have been directed at alternative strategies such as the synthetic lethal approach, which aims at targeting proteins that are crucial for the survival of tumor cells with an activated Ras protein. Theoretically, it may be possible to kill tumorigenic cells expressing a mutated Ras gene without affecting normal cells (55).

These are just few examples of the recent efforts to relocate the modern achievements in cancer research into the diagnosis and therapy fields. However, much more is still to be done. More genomics data, more animal-models that are suitable, more implemented personalized medicine trials, and new expertise such as onco-bio-informatics, will be crucial to implement onco-knowledge into clinical evaluation. Moreover, scientists should always consider the ethical, legal, and social implications that clinical-genomics raise. For instance, the high costs of such therapeutic and diagnostic approaches that can put a financial strain on people selecting treatments that they can or cannot afford. This, in the end, could determinate who may or may not undergo the most appropriate cure.

The purpose of this review is to underline past developments that may help to achieve important new goals in cancer research. Interpreting and construing the past giants theories relating to the modern achievements have been a quite exciting, but easy task. However, predicting the future of cancer research, which is based on current and past knowledge, is difficult and should take in account two considerations. The first is the speed of developments: nowadays research moves so fast. The second is the complexity: the modern technologies generate thousands of results, and each one is a small element looking for its place in an extraordinary puzzle.
Therefore, these peculiarities of current cancer research suggest that future investigations should be based on worldwide cooperation, the best 'technology' for reaching the daring goals to understand cancer and 'eventually' cure it.

\section{Conclusions}

Cancer research evolved down a long path, since Hippocrates proposed his theory of black bile. Boveri's vision of cancer as a genetic disease a century ago, cloning of the first human oncogene almost thirty years ago, and decoding of the human genome almost ten years ago, represent major steps in the understanding of cancer. Nowadays, DNA sequencing and gene expression profiles may have a relevant prognostic value in a wide variety of malignancies. For instance, DNA copy number variations and gene expression signatures are employed to define tumor subtypes and as prognostic indicators in chronic myeloid leukaemia, breast cancers and other tumors (56, 57). Bioinformatics technologies and cancer databases are used to combine molecular, clinical, and population data for diagnostic purposes and for formulating therapeutic strategies. By analyzing individual genetic profiles, it may be possible to foresee risks of cancer development and devise personalized therapies $(58,59)$. We are now in the era of cancer 'omics', which investigate genomes, epigenomes, methylomes, transcriptomes, miRnomes, metabolomes, proteomes and so on, easily accumulating ponderous amounts of information, often causing intractable problems (46). There are still huge gaps among these large datasets and in the understanding of cancer biology. How the cancer genomes and gene expression programs interact to dictate cancer cell behaviour, the role of cancer stem cells, the mutual influence of the cancer cells with the cells of the microenvironment, are all aspects that have to be confronted.

Still cancer is an unresolved problem, and researchers must work harder to get to the root of all these open ended questions.

Confucio said, 'Study the past if you would define the future'. Past scientific achievements could represent the milestones for building future bridges along the path of cancer research understanding, 'we should not forget the past'.

\section{Acknowledgements}

We wish to dedicate this review in memory of Dr. Hanna Michalek, a great scientist and friend.

We also wish to thank Dr. Carlo Pini, Head of the National Center for Immunobiologicals Research and Evaluation, for his encouragement and advice.

We would like to thank the Bi.Ge.A.-Bologna University for their permission to reproduce the book 
cover of Zur Frage der Entstehung Maligner Tumoren, and Massimo Delle Femmine for the graphic support.

We would finally like to thank Maurice Di Santolo for the English revision of the final draft.

\section{Competing Interests}

The authors have declared that no competing interest exists.

\section{References}

1. Hajdu SI. A note from history: landmarks in history of cancer, Part 1. Cancer. 2011; 117:1097-102. doi: 10.1002/cncr.25553.

2. Mitrus I, Bryndza E, Sochanik A, Szala S. Evolving models of tumor origin and progression. Tumor Biol. 2012; 33:911-7. doi: 10.1007/s13277-012-0389-0.

3. Henschen F. Yamagiwa's tar cancer and its historical significance. From Percival Pott to Katsusaburo Yamagiwa. Gann. 1968; 59:447-51.

4. Boveri T. Zur frage der entstehung maligner tumoren. Jena, Germany: Gustav Fisher; 1914

5. Boveri T. Concerning the origin of malignant tumours by Theodor Boveri. Translated and annotated by Henry Harris. J Cell Sci. 2008; 121 (Suppl 1): 1-84. doi: $10.1242 /$ jcs. 025742 .

6. Balmain A. Cancer genetics: from Boveri and Mendel to microarrays. Nat Rev Cancer. 2001; 1:77-82. doi:10.1038/35094086.

7. Javier RT, Butel JS. The history of tumor virology. Cancer Res. 2008; 68:7693-706. doi: 10.1158/0008-5472.CAN-08-3301.

8. Kalland KH, Xi-Song Ke XS, Øyan AM. Tumour virology - history, status and future challenges. APMIS. 2009; 117: 382-99. doi: 10.1111/j.1600-0463.2009.02452.x

9. Barbacid M. ras genes. Annu Rev Biochem. 1987; 56:779-827.

10. Temin HM, Rubin H. Characteristics of an assay for Rous sarcoma virus and Rous sarcoma cells in tissue culture. Virology. 1958; 6:669-88.

11. Watson JD, Crick FH. Molecular structure of nucleic acids; a structure for deoxyribose nucleic acid. Nature. 1953; 171:737-8.

12. Holliday R. The early years of molecular biology: personal recollections. Notes Rec R Soc Lond. 2003; 57:195-208. doi: 10.1098/rsnr.2003.0206.

13. Crawford LV, Crawford EM. The properties of Rous sarcoma virus purified by density gradient centrifugation. Virology. 1961; 13:227-32.

14. Drayton HA. The inactivation by organic solvents and detergents of partially purified Rous I virus preparations. Br J Cancer. 1961; 15: 348-53.

15. Temin HM. The effects of actinomycin $\mathrm{D}$ on growth of Rous sarcoma virus in vitro. Virology. 1963; 20:577-82.

16. Temin HM. The participation of DNA in Rous sarcoma virus production. Virology. 1964; 23:486-94.

17. Temin HM. Malignant transformation in cell cultures. Health Lab Sci 1964; 1:79-83.

18. Huebner RJ, Todaro GJ. Oncogenes of RNA tumor viruses as determinants of cancer. Proc Natl Acad Sci USA. 1969; 64:1087-94.

19. Baltimore D. RNA-dependent DNA polymerase in virions of RNA tumour viruses. Nature. 1970; 226:1209-11.

20. Temin HM, Mizutani S. RNA-dependent DNA polymerase in virions of Rous sarcoma virus. Nature. 1970; 226:1211-3.

21. Stehelin D, Varmus HE, Bishop JM, Vogt PK. DNA related to the transforming gene(s) of avian sarcoma viruses is present in normal avian DNA. Nature. 1976; 260:170-3.

22. Weinberg RA. The molecular basis of oncogenes and tumor suppressor genes. Ann N Y Acad Sci. 1995; 758:331-8. doi: 10.1111/j.1749-6632.1995.tb24838.

23. Ames BN. Mutagenesis and carcinogenesis: endogenous and exogenous factors. Environ Mol Mutagen. 1989; 14 (Suppl 16):S66-S77.

24. Graham FL, van der Eb AJ. A new technique for the assay of infectivity of human adenovirus 5 DNA. Virology. 1973; 52:456-67.

25. Weinberg RA. Use of transfection to analyze genetic information and malignant transformation. Biochim Biophys Acta. 1981; 651: 25-35.

26. Parada LF, Tabin CJ, Shih C, Weinberg RA. Human EJ bladder carcinoma oncogene is homologue of Harvey sarcoma virus ras gene. Nature. 1982; 297:474-8.

27. Santos E, Tronick SR, Aaronson SA, Pulciani S, Barbacid M. T24 human bladder carcinoma oncogene is an activated form of the normal human homologue of BALB- and Harvey-MSV transforming genes. Nature. 1982; $298: 343-7$.

28. Fasano O, Taparowsky E, Fiddes J, Wigler M, Goldfarb M. Sequence and structure of the coding region of the human H-ras-1 gene from T24 bladder carcinoma cells. J Mol Appl Genet. 1983; 2:173-80.

29. Eva A, Tronick SR, Gol RA, Pierce JH, Aaronson SA. Transforming genes of human hematopoietic tumors: frequent detection of ras-related oncogenes whose activation appears to be independent of tumor phenotype. Proc Natl Acad Sci USA. 1983; 80:4926-30.

30. Pulciani S, Santos E, Lauver AV, Long LK, Aaronson SA, Barbacid M. Oncogenes in solid human tumours. Nature. 1982; 300: 539-42.
31. Sukumar S, Pulciani S, Doniger I, DiPaolo JA, Evans CH, Zbar B, Barbacid M. A transforming ras gene in tumorigenic guinea pig cell lines initiated by diverse chemical carcinogens. Science. 1984; 223:1197-9.

32. de Klein A, van Kessel AG, Grosveld G, Bartram CR, Hagemeijer A, Bootsma D, Spurr NK, Heisterkamp N, Groffen J, Stephenson JR. A cellular oncogene is translocated to the Philadelphia chromosome in chronic myelocytic leukaemia. Nature. 1982; 300:765-7.

33. Nasi S, Ciarapica R, Jucker R, Rosati J, Soucek L. Making decisions through Myc. FEBS Lett. 2001; 490:153-62. doi: 10.1016/S0014-5793(01)02118-4.

34. Molyneux EM, Rochford R, Griffin B, Newton R, Jackson G, Menon G, Harrison CJ, Israels T, Bailey S. Burkitt's lymphoma. Lancet. 2012; 379:1234-44. doi: 10.1016/S0140-6736(11)61177.x

35. Brison O. Gene amplification and tumor progression. Biochim Biophys Acta. 1993; 1155:25-41. doi: 10.1016/0304-419X(93)90020.

36. Stanbridge EJ, Der CJ, Doersen CJ, Nishimi RY, Peehl DM, Weissman BE, Wilkinson JE. Human cell hybrids: analysis of transformation and tumorigenicity. Science 1982; 215:252-9.

37. Huang HI, Yee JK, Shew JY, Chen PL, Bookstein R, Friedmann T, Lee EY, Lee $\mathrm{WH}$. Suppression of the neoplastic phenotype by replacement of the RB gene in human cancer cells. Science. 1988; 242: 1563-6.

38. Knudson AG Jr. Genetic predisposition to cancer. Cancer Detect Prev. 1984; 7:1-8.

39. Knudson AG. Hereditary cancer: two hits revisited. J Cancer Res Clin Oncol. 1996; 122: 135-40.

40. Sun W, Yang J. Functional Mechanisms for Human Tumor Suppressors. J Cancer. 2010; 1: 136-40. doi:10.7150/jca.1.136.

41. Park Y J, Claus R, Weichenhan D, Plass C. Genome-wide epigenetic modifications in cancer. Prog Drug Res. 2011; 67:25-49.

42. Collot-Teixeira S, Bass J, Denis F, Ranger-Rogez S. Human tumor suppressor p53 and DNA viruses. Rev Med Virol. 2004; 14:301-19. doi: 10.1002/rmv.431

43. Dulbecco R. A turning point in cancer research: sequencing the human genome. Science. 1986; 231: 1055-6.

44. Johansen Taber KA, Dickinson BD, Wilson M. The promise and challenges of next-generation genome sequencing for clinical care. JAMA Intern Med. 2014; 174:275-80. doi: 10.1001/jamainternmed.2013.12048

45. Kristensen VN, Lingjærde OC, Russnes HG, Vollan HK, Frigessi A, Børresen-Dale AL. Principles and methods of integrative genomic analyses in cancer. Nat Rev Cancer. 2014; 14:299-313. doi: 10.1038/nrc3721.

46. Weinberg RA. Coming full circle-from endless complexity to simplicity and back again. Cell. 2014; 157:267-71. doi: 10.1016/j.cell.2014.03.004

47. Mallardo M, Poltronieri P, D'Urso O. Non-protein coding RNA biomarkers and differential expression in cancers: a review. J Exp Clin Cancer Res. 2008; 27:19. doi:10.1186/1756-9966-27-19.

48. Feng Z, Kagan J, Pepe M, Thornquist M, Ann Rinaudo J, Dahlgren J, Krueger K, Zheng Y, Patriotis C, Huang Y, Sorbara L, Thompson I, Srivastava S. The Early Detection Research Network's Specimen reference sets: paving the way for rapid evaluation of potential biomarkers. Clin Chem. 2013; 59:68-74. doi: 10.1373/clinchem.2012.185140.

49. Chen Y, McGee Y, Chen X, Doman TN, Gong X, Zhang Y, Hamm N, Ma X, Higgs R E, Bhagwat SV, Buchanan S, Peng S, Staschke KA, Yadav V, Yue Y, Kouros-Mehr H. Identification of Druggable Cancer Driver Genes Amplified across TCGA Datasets. PLoS One. 2014; 9:e98293. doi: 10.1371/journal.pone.0098293.

50. Chen X, Sun L, Cong Y, Zhang T, Lin Q, Meng Q, Pang H, Zhao Y, Li Y, Cai L, Dong $X$. Baseline staging tests based on molecular subtype is necessary for newly diagnosed breast cancer. J Exp Clin Cancer Res. 2014; 33:28. doi: 10.1186/1756-9966-33-28

51. Idikio HA. Human Cancer Classification: A Systems Biology- Based Model Integrating Morphology, Cancer Stem Cells, Proteomics, and Genomics. J Cancer 2011; 2:107-115. doi:10.7150/jca.2.107.

52. Chen K, Huang YH, Chen JL. Understanding and targeting cancer stem cells: therapeutic implications and challenges. Acta Pharmacol Sin. 2013, 34:732-40. doi: 10.1038 /aps.2013.27.

53. Pan X. Single Cell Analysis: From Technology to Biology and Medicine. Single Cell Biol. 2014; 3(1): 106. doi: 10.4172/2168-9431.1000106.

54. Soucek L, Whitfield J, Martins CP, Finch AJ, Murphy DJ, Sodir NM, Karnezis AN, Swigart LB, Nasi S, Evan GI. Modelling Myc inhibition as a cancer therapy. Nature. 2008; 455:679-83. doi: 10.1038/nature07260.

55. Takashima A, Faller DV. Targeting the RAS oncogene. Expert Opin Ther Targets. 2013; 17:507-31. doi: 10.1517/14728222.2013.764990.

56. Dos Anjos Pultz B, da Luz FA, de Faria PR, Oliveira AP, de Araújo RA, Silva MJ. Far beyond the usual biomarkers in breast cancer: a review. J Cancer. 2014; 5:559-71. doi:10.7150/jca.8925.

57. Hernández-Boluda JC, Cervantes F. Prognostic factors in chronic myeloid leukaemia. Best Pract Res Clin Haematol. 2009; 22:343-53. doi: 10.1016/j.beha 2009.04.005

58. Shaikh AR, Butte AJ, Schully SD, Dalton WS, Khoury MJ, Hesse BW. Collaborative biomedicine in the age of big data: the case of cancer. J Med Internet Res. 2014; 16: e101. doi: 10.2196/jmir.2496.

59. Domvri K, Zarogoulidis P, Darwiche K, Browning RF, Li Q, Turner JF, Kioumis I, Spyratos D, Porpodis K, Papaiwannou A, Tsiouda T, Freitag L, Zarogoulidis K. Molecular targeted drugs and biomarkers in NSCLC, the evolving role of individualized therapy. J Cancer. 2013; 4:736-54. doi:10.7150/jca. 7734 